Annales Geophysicae (2003) 21: 2323-2328 C European Geosciences Union 2003

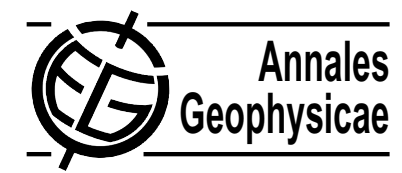

\title{
Study of mid-latitude nighttime enhancement in F-region electron density using tomographic images over the UK
}

\author{
R. S. Dabas ${ }^{1}$ and L. Kersley ${ }^{2}$ \\ ${ }^{1}$ Radio and Atmospheric Sciences Division, National Physical Laboratory, New Delhi-110012, India \\ ${ }^{2}$ Department of Physics, University of Wales, Aberystwyth, SY23, 3BZ, UK
}

Received: 27 August 2002 - Revised: 24 April 2003 - Accepted: 13 May 2003

\begin{abstract}
Nighttime enhancements in ionospheric electron content (IEC)/peak electron density $(\mathrm{Nm} \mathrm{F} 2)$ have been studied by various workers in the equatorial anomaly and midlatitude regions. Such studies give an idea about their enhancement over that location only. In the present study tomographic images over the UK, which give a latitudinal versus height distributions of ionospheric electron density in a much wider area, have been used to study the anomalous increases in nighttime F-region electron density at mid-latitudes. From the analysis of four seasonal representative months (November 1997, March, June and October 1998) data it was noted that the majority of the cases of nighttime enhancements were observed after local midnight, with a maximum between 03:00-04:00 LT in the month of November 1997. Enhancements were observed mostly between $45-50^{\circ} \mathrm{N}$ latitudes, and their positions are not affected by magnetic activity $\left(K_{p}\right)$ variations, whereas the separation between the midlatitude trough and enhancement decreases with increases in magnetic activity. This finding shows that only the trough moves equatorward with the increase in magnetic activity. It is also noted that the electron density gradient from the trough to the enhancement increases with an increase in $K_{p}$. Results are discussed in terms of downward plasma transport from the protonosphere to the ionosphere and the nighttime neutral winds.
\end{abstract}

Key words. Ionosphere (mid-latitude ionosphere; modeling and forecasting; instruments and techniques)

\section{Introduction}

It has been known for a long time that both the Ionospheric Electron Content (IEC) and peak electron density of the F-region $(N m \mathrm{~F} 2)$ show anomalous nighttime enhancement, both in the equatorial anomaly region, as well as in the midlatitude ionosphere and this has been studied by various re-

Correspondence to: R. S. Dabas

(rajdabas@mail.nplindia.ernet.in) searchers (Evans, 1965; Davies et al., 1979; Janve et al., 1979; Essex and Klobuchar, 1980; Kersley et al., 1980; Joshi and Iyer, 1990; Bailey et al., 1991; Balan et al., 1991). In the equatorial anomaly region the primary source of such nighttime enhancement is the evening increase in the upward $\boldsymbol{E} \times \boldsymbol{B}$ drift at the equator (Anderson and Klobuchar, 1983; Balan et al., 1994). At mid-latitudes the primary source has been identified as a downward flow of plasma from the protonosphere to the ionosphere (Bailey et al., 1991). In addition, neutral air winds modulate these enhancements at all latitudes (Anderson and Klobuchar, 1983; Bailey et al., 1991). At mid-latitudes Essex and Klobuchar (1980) reported that nighttime IEC enhancements, which they observed mostly around 03:00 LT during the December months, are accompanied by large increases in peak density of the $\mathrm{F}$ layer and a lowering of layer height, which shows that the enhancement takes place in the F-region of the ionosphere. Use of IEC and $N m \mathrm{~F} 2$ in such studies tells us about such enhancements over that particular location only, but in reality, it is observed in a wider area in space. Therefore, it is difficult to tell exactly where in the latitude range its peak occurs. In the recent past the technique of tomographic imaging of the ionosphere, which gives latitude versus height distribution of ionospheric electron density, has proved its potential in studying the ionospheric properties, like the mid-latitude trough (Kersley et al., 1997; Pryse et al., 1998 and references therein), as well as its modeling in a much wider area. In the present study tomographic images over the UK have been used to study the anomalous increases in nighttime F-region electron density at mid-latitudes.

\section{Data and results}

Ionospheric tomography uses total electron content measurements made at a linear chain of stations, aligned approximately along a common geographic meridian. The observations are then reconstructed in an inversion algorithm to create an image of the spatial distribution of the electron den- 


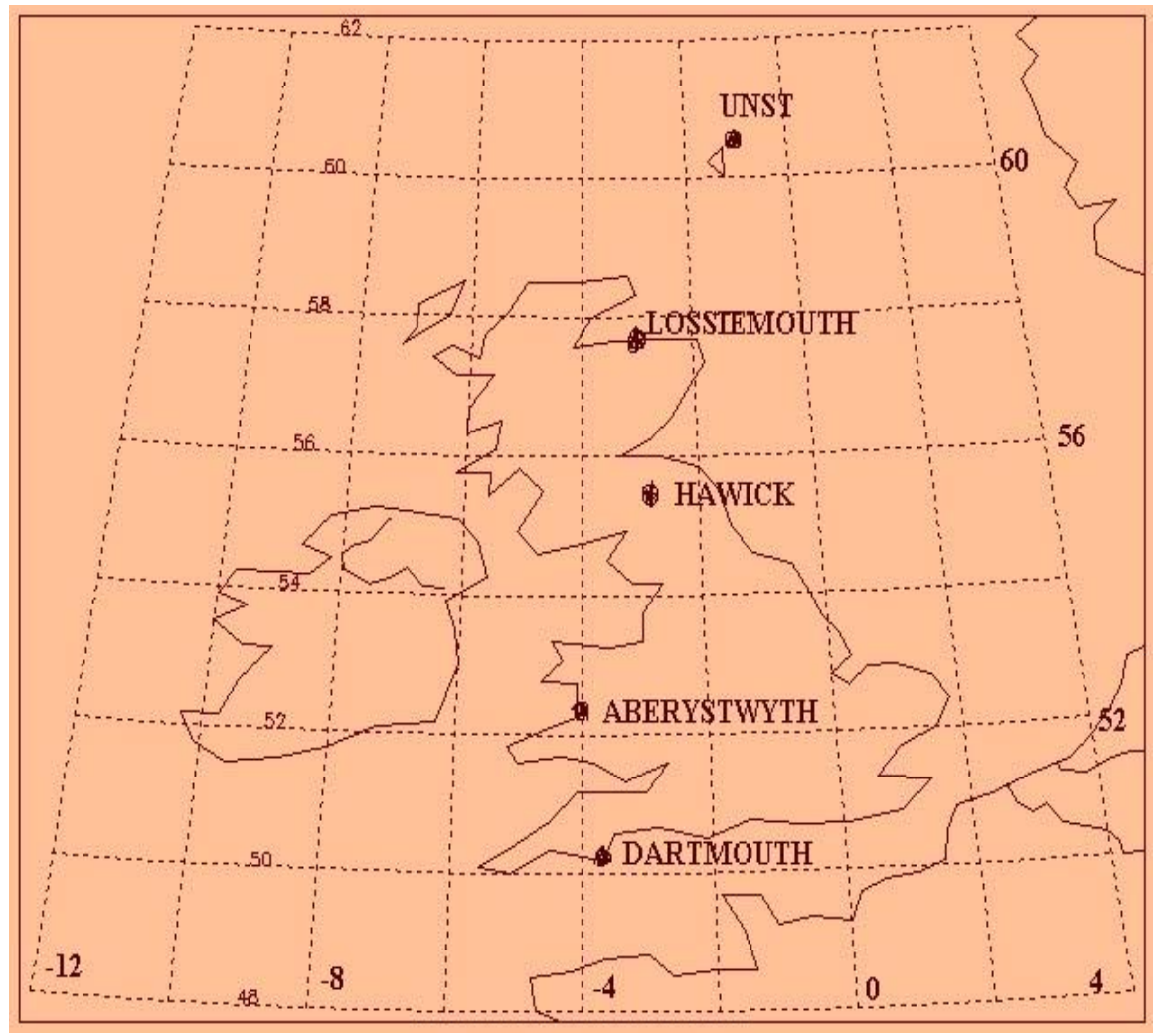

Fig. 1. Map showing the locations of the sites with tomography receiving equipment in the UK.

sity as a function of latitude and height. The chain of five automated receiving stations in the UK (Dartmouth, Aberystwyth, Hawick, Lossiemouth and Unst), shown by circles in Fig. 1, monitored the phase-coherent radio signals on 150 and $400 \mathrm{MHz}$, transmitted by satellites in the Navy Ionospheric Monitoring System (NIMS), to measure the total electron content (TEC) along many intersecting ray paths. Further information on the development of experimental radio tomographic imaging can be found in many publications, including Kersley and Pryse (1994), Walker et al. (1996), and Kersley et al. (1997). The tomographic images used in the present study were reconstructed by the DIT/ART method, discussed in earlier papers, and created in a pixelised grid of some $0.25^{\circ}$ in latitude and $15 \mathrm{~km}$ in altitude. The Discrete Inversion Theory (DIT) procedure described by Fremouw et al. (1992) was used to reconstruct the large-scale background features in the ionosphere, while subsequent processing by the Algebraic Reconstruction Technique (ART) formed the smaller scale density structures. In the present study four months of data (November 1997, March, June and October 1998), roughly representing different seasons, has been used to study the nighttime enhancement in ionospheric electron density over mid-latitudes. Two examples of the nighttime enhancements observed on 16 October 1998 at 02:17 UT and 27 November 1998 at 00:17 UT, along with the mid-latitude troughs, are shown in Figs. 2a and b, which clearly show a well-defined increase in F-region electron density around $50^{\circ} \mathrm{N}$ latitude, around $300 \mathrm{~km}$ altitude in the first case and around $47^{\circ} \mathrm{N}$ latitude in the second case, whereas the trough locations were around $62^{\circ} \mathrm{N}$ and $60^{\circ} \mathrm{N}$, respectively. Both these days were magnetically quiet days, and $K_{p}$ was one and zero, respectively. During the period of four months of data reported here, a total of 46 cases of nighttime enhancement in F-region electron density were observed. From the analysis of data we observed the following main points:

(a) It is noted that at mid-latitude the largest number of cases of nighttime enhancement in peak electron density $(N m \mathrm{~F} 2)$ were observed after local midnight with a maximum occurrence between 03:00 to 04:00 LT (see Fig. 3a). In the months of March and June 1998 only a few cases of enhancements are observed and the majority of them are observed in the months of October 1998 and November 1997 only (see Fig. 3b). During the period of four months of observation reported here, F10.7 cm flux values varied from 90 to 130 only.

(b) Figure 4 shows the plot of the latitudes of peak electron density enhancements versus local time. From the figure it is noted that enhancements in peak electron density are observed mainly between $42-53^{\circ} \mathrm{N}$ latitudes, centered around $48^{\circ} \mathrm{N}$ and most of these cases occurred after local midnight.

(c) To examine the effect of magnetic activity on their latitudinal occurrence, the average values of the latitude of the enhancement corresponding to each $K_{p}$ level are 

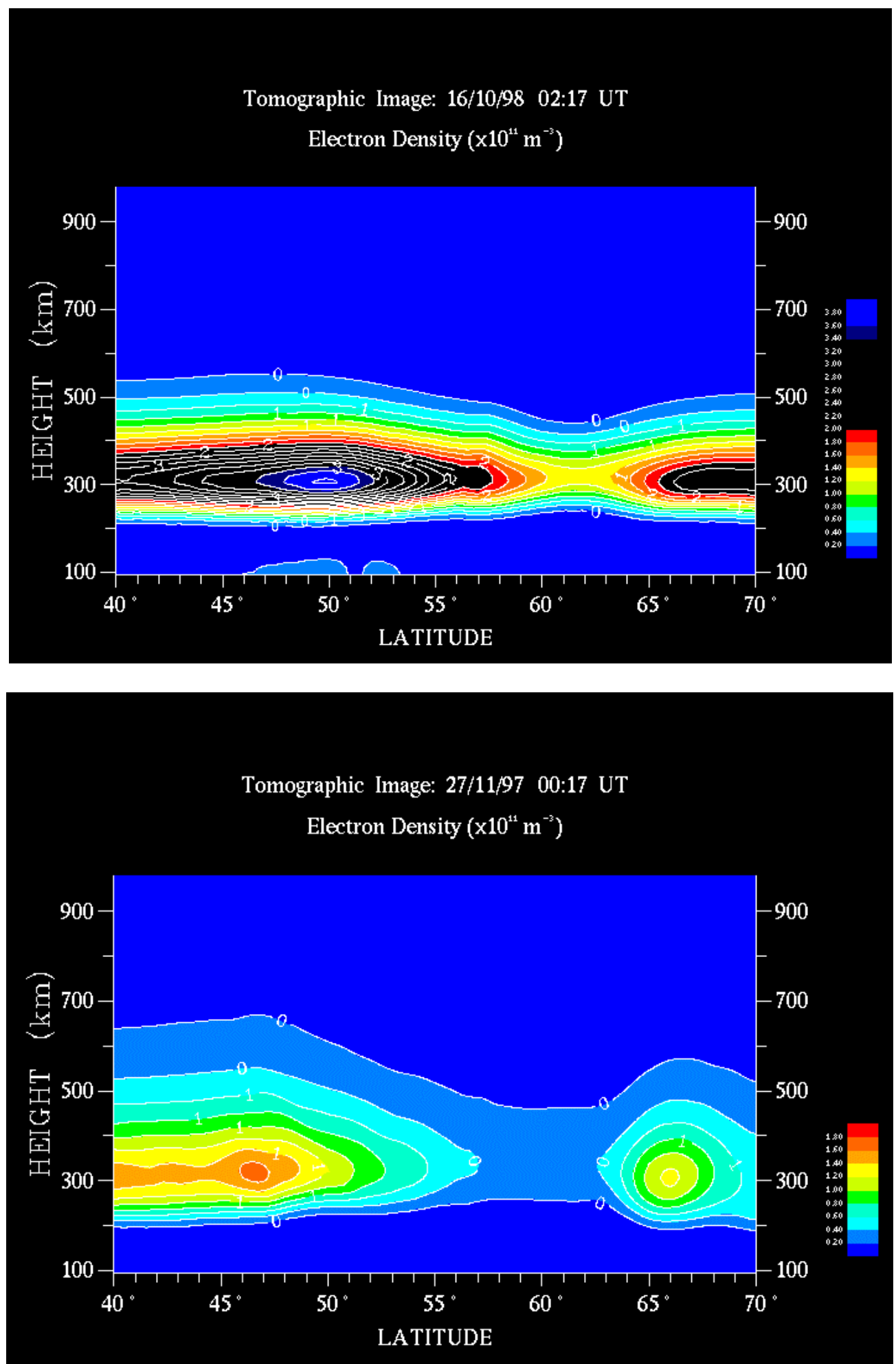

Fig. 2. Examples of mid-latitude nighttime enhancements in F-region electron density of the ionosphere, along with the occurrences of the mid-latitude trough (a) on 16 October 1998 at 02:17 UT and (b) on 27 November 1997 at 00:17 UT. 


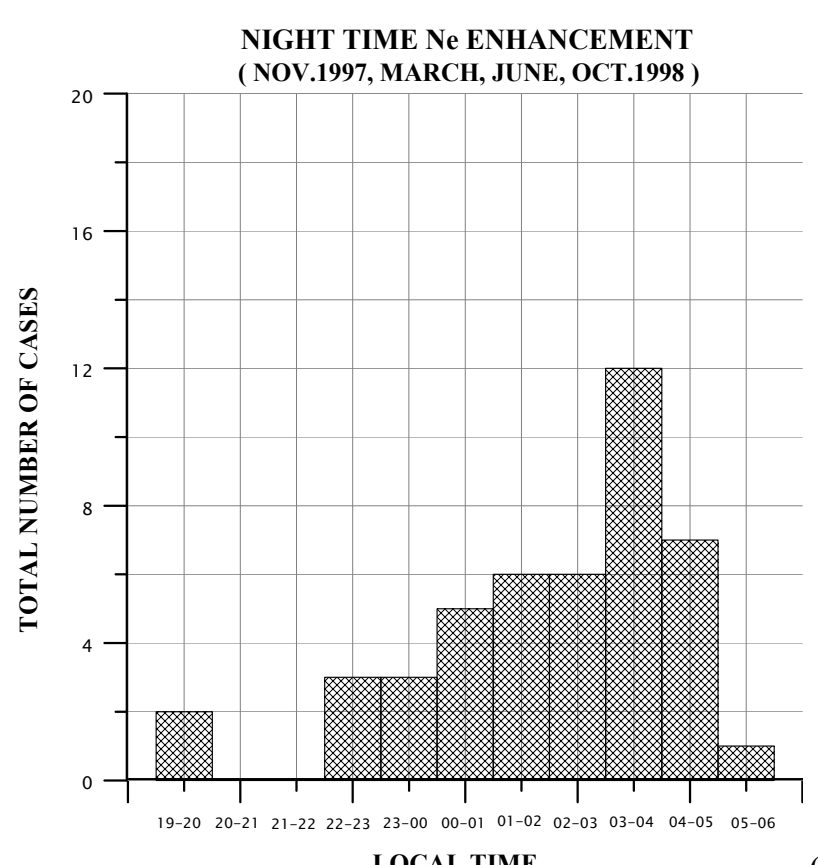

LOCAL TIME

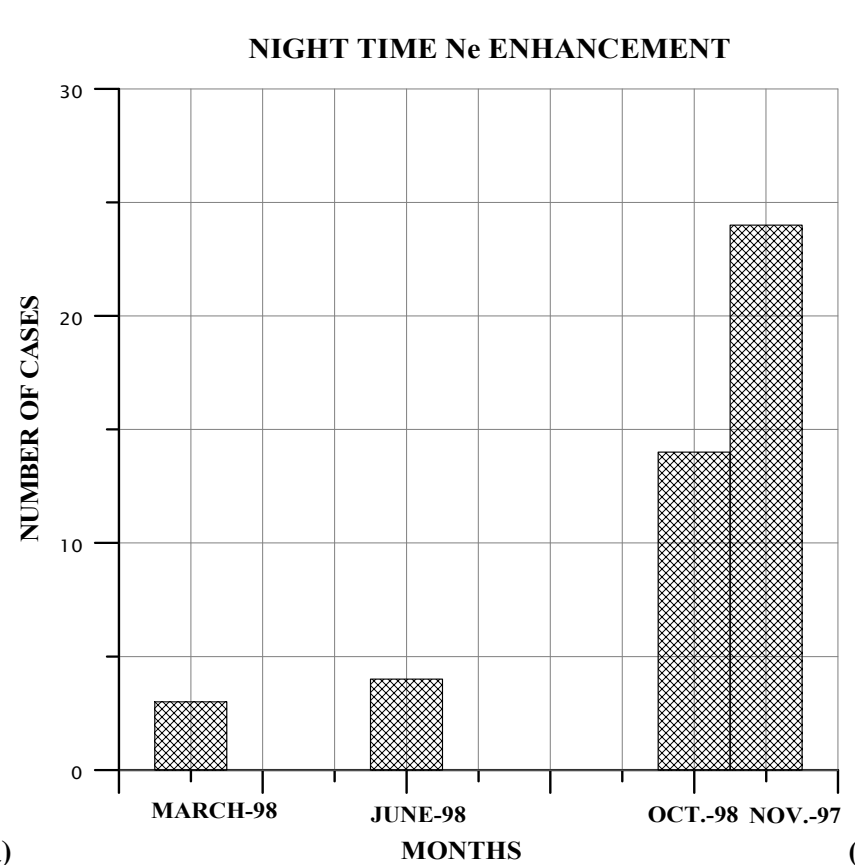

(b)

Fig. 3. Histograms showing (a) local time occurrences of nighttime enhancements and (b) their monthly occurrences during the four representative months.

plotted as a function of $K_{p}$, as shown in Fig. 5. It is noted that their latitudinal position is hardly affected by increases in magnetic activity i.e. $K_{p}$.

(d) The latitudinal separation between the mid-latitude trough minimum and the peak enhancement is also calculated in each case and the average values of this separation within each $K_{p}$ level are calculated and plotted against $K_{p}$ in Fig. 6 . It is noted that the latitude separation between mid-latitude trough and the nighttime enhancement decreases with the increase in magnetic activity, $K_{p}$. This is due to the fact that with the increase in magnetic activity the trough position shifted equatorward.

(e) The electron density gradient between the trough minimum and the peak enhancement is also calculated in each case by dividing the difference in electron density between them by the latitudinal separation between the two. The mean value of the gradients is calculated at each $K_{p}$ level, i.e. $0,1,2$ etc. and when these average are plotted against $K_{p}$ (see Fig. 7), it is noted that the value of the gradient increases with the increase in $K_{p}$. This is due to the fact that with the increase in $K_{p}$, the trough position moves towards equatorward without affecting the enhancement location and thereby increases the electron density gradients from trough minimum to peak enhancement.

\section{Discussion}

From the results described in the previous section it is noted that most of the cases of nighttime enhancements in ionospheric electron density are observed during the winter month of November 1997 in the post-midnight hours, with a maximum between 03:00-04:00 LT. Latitude-wise majority of them were observed between $45^{\circ}$ to $50^{\circ} \mathrm{N}$ latitudes, and their positions are least affected by the variations in the $K_{p}$ values. These results are in line with those reported by other workers, e.g. Davies et al. (1979); Essex and Klobuchar (1980); Balan et al. (1994), except that local time occurrences vary. Important mechanisms for nighttime enhancements at mid-latitudes are field-aligned plasma flow, crossL plasmaspheric compression and neutral air winds interactions. In the winter hemisphere the field-aligned plasma flow is downwards, i.e. from protonosphere to the ionosphere, particularly during post-midnight hours, and the duration of the downward flow decreases with increasing solar activity (Evans and Holt, 1978). Thus, the protonosphere supplies ionization to the winter hemisphere. Down diffusion can be enhanced by cross L-plasmaspheric compression, since a westward electric field will move plasma from higher Lshells with the subsequent effect that the plasma pressure in the lower L-shells will increase. The effect of the excess plasma pressure is to increase the downward diffusion of plasma, which, in turn, increases the ionospheric content at both ends of the L-shell (Davies et al., 1979). At midlatitudes during all seasons the meridonal neutral wind is equatorward during nighttime and attains its maximum speed 


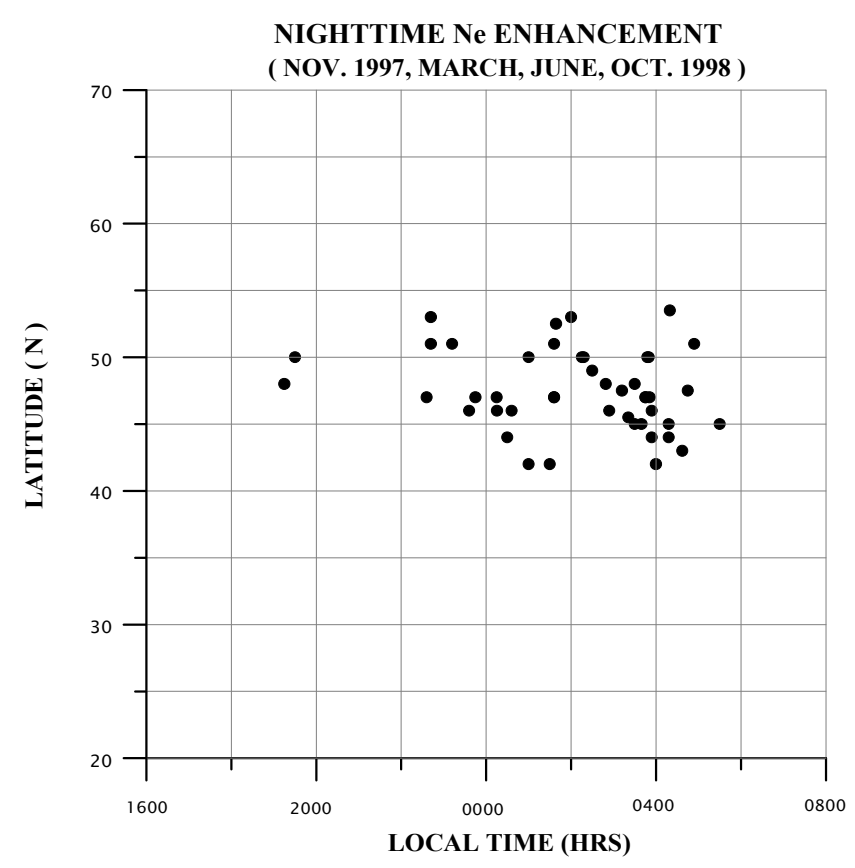

Fig. 4. Plot showing the latitudes of nighttime enhancements versus local time.

at around midnight (Hernandez and Roble, 1984). Thus, the strong downward diffusion of plasma from the protonosphere, combined with the neutral air winds interactions, can easily produce enhancements in nighttime ionospheric electron density at mid-latitudes during winter at solar minimum. Bailey et al. (1990a) have modeled winter nighttime values of TEC for ray paths, which traverse the mid-latitude ionosphere. The modeled values for magnetically quiet solar minimum conditions show enhancements, which peak during the post-midnight period, when the downward flow of plasma through the $2500 \mathrm{~km}$ altitude level exceeds that which is lost chemically at lower altitudes. The enhancements are found to be strong near $40^{\circ}$ latitude and weak near $60^{\circ}$ latitude. The results of these authors are in agreement with the present observations.

\section{Summary}

Ionospheric tomography uses TEC measurements at a chain of stations along a common meridian, to produce an image of the spatial distribution of the electron density as a function of latitude and height. As compared to other techniques the main advantage in ionospheric tomography is that it gives a snapshot picture of latitudinal versus height distributions of ionospheric electron density in a much wider area and is useful to characterize large-scale ionospheric features, like mid-latitude trough, ionization anomaly etc. The present study utilized the tomographic images over the UK to study the anomalous increases in nighttime F-region electron density at mid-latitudes. It is observed that the majority

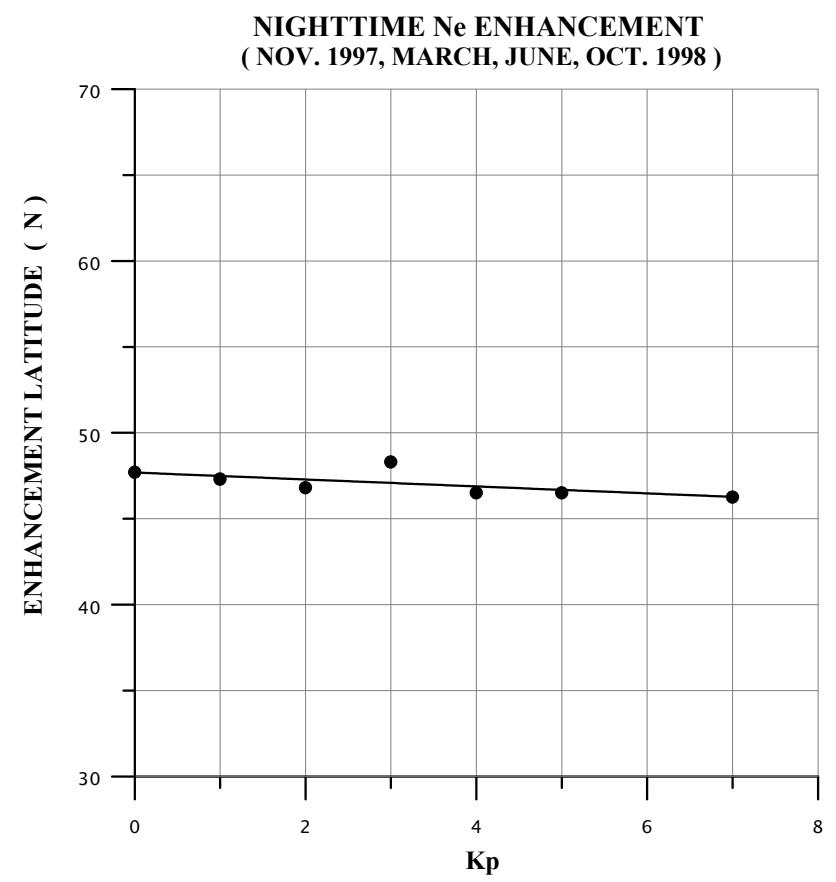

Fig. 5. Variations of enhancement latitudes with $K_{p}$. Average of latitudes with each $K_{p}$ index are plotted here.

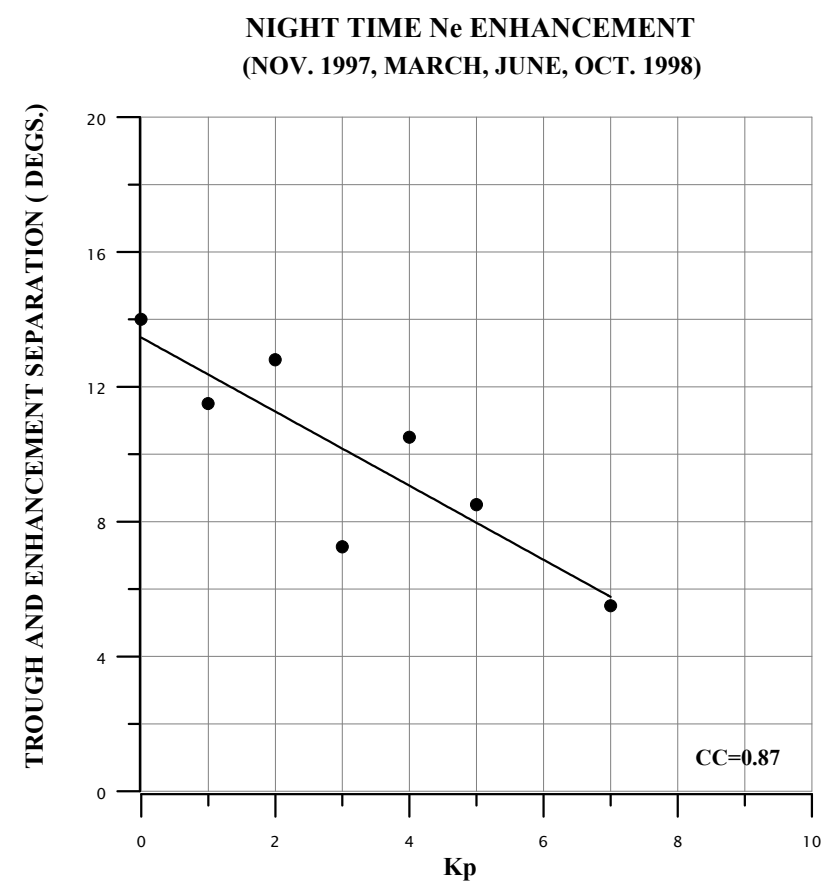

Fig. 6. Variations of latitudinal separation between trough minimum and peak enhancement with $K_{p}$. Here, again, average values with each $K_{p}$ index are shown.

of the cases of nighttime enhancements were observed after local midnight, with a maximum between 03:00-04:00 LT in the month of November 1997. Latitudinally these were confined to primarily between $45-50^{\circ} \mathrm{N}$, and their positions 


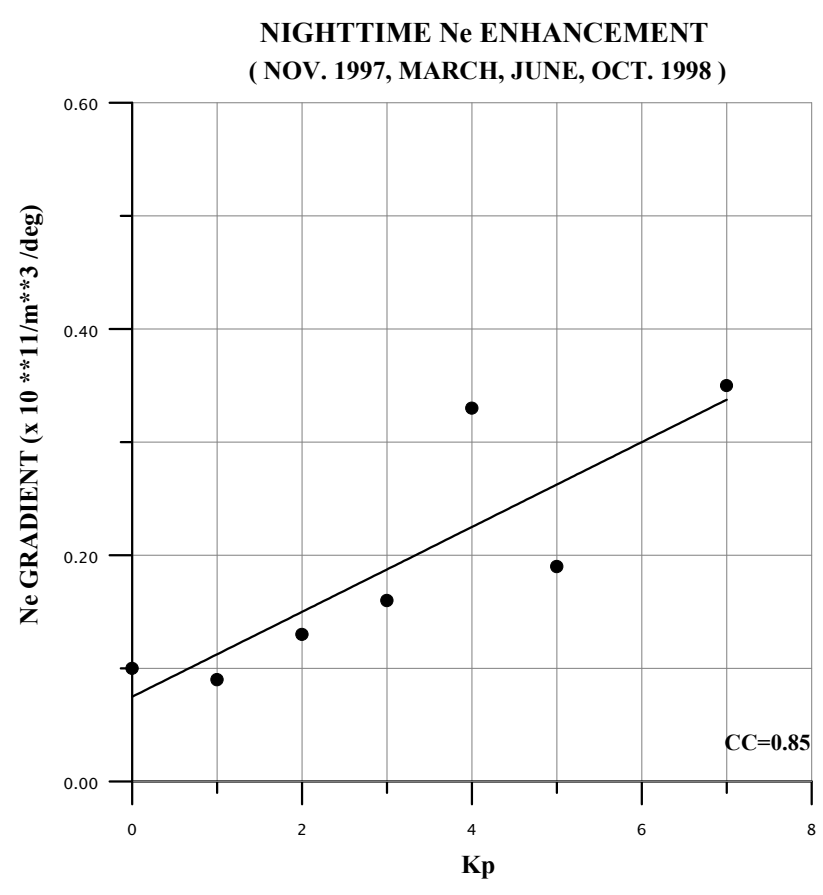

Fig. 7. Variations in electron density $\left(N_{e}\right)$ gradients from trough minimum to peak enhancement with $K_{p}$.

were not affected by magnetic disturbances, whereas the separation between the mid-latitude trough and the enhancement decreases with increases in magnetic activity, indicating the equatorward movement of the trough with the increases in magnetic activity, producing a sharp electron density gradient from trough to enhancement. It is concluded that the ionospheric tomography technique gives a better representation of the regional structure of the ionosphere.

Acknowledgements. RSD acknowledge the support of the Leverhulme Trust in the provision of a Fellowship to work at UWA. The experimental observations used in the present study were supported in part by DERA, Malvern, UK.

Topical Editor M. Lester thanks S. Radicella and R. Leitinger for their help in evaluating this paper.

\section{References}

Anderson, D. N. and Klobuchar, J. A.: Modeling the total electron content observations above Ascension Island, J. Geophys. Res. 88, 8020-8024, 1983.

Balan, N., Bailey, G. J., and Balachandran Nair, R.: Solar and magnetic activity effects on the latitudinal variations of nighttime TEC enhancement, Ann. Geophysicae, 9, 60-69, 1991.
Balan, N., Bailey, G. J., Balachandran Nair, R., and Titheridge, J. E.: Nighttime enhancement in ionospheric electron content in the northern and southern hemispheres, J. Atmos. Terr. Phys., 56, 67-79, 1994.

Bailey, G. J., Sellek, R., and Balan, N.: A modeling study of nighttime enhancements in TEC during winter at solar minimum. Proc. URSI International Beacon Satellite Symposium, Tucuman, Argentina, March 1990, 229-236, 1990a.

Bailey, G. J., Sellek, R., and Balan, N.: The effect of interhemispheric coupling on nighttime enhancements in ionospheric total electron content during winter at solar minimum, Ann. Geophysicae, 9, 738-747, 1991.

Davies, K., Anderson, D. N., Paul, A. K., Degenhardt, W., Hartmann, G. K., and Leitinger, R.: Nighttime increases in total electron content observed with the ATS6 radio beacon, J. Geophys. Res. 84, 1536-1542, 1979.

Essex, E. A. and Klobuchar, J. A.: Mid-latitude winter nighttime increases in the total electron content of the ionosphere, J. Geophys. Res. 85, 6011-6020, 1980.

Evans, J. V.: Cause of the mid-latitude winter night increase in $f o \mathrm{~F} 2$, J. Geophys. Res.70, 4331-4346, 1965.

Evans, J. V. and Holt, J. M.: Nighttime proton flux at Millstone Hill, Planet. Space Sci., 26, 727-744, 1978.

Fremouw, E. J., Secan, J. A., and Howe, B. M.: Application of stochastic inversion theory to ionospheric tomography, Radio Sci., 17, 721-732, 1992.

Hernandez, G. and Roble, R. G.: The geomagnetic quiet nighttime thermospheric wind pattern over Fritz Peak observatory during solar cycle minimum and maximum, J. Geophys. Res., 89, 327337, 1984.

Janve, A. V., Rai, R. K., Deshpande, M. R., Rastogi, R. G., Jain, A. R., Singh, M., and Grum, H. S.: On the nighttime enhancement in ionospheric total electron content at low latitudes, Ann. Geophysicae, 35, 159, 1979.

Joshi, H. P. and Iyer, K. N.: On the nighttime anomalous enhancement in ionospheric electron content at lower mid-latitude during solar maximum, Ann. Geophysicae, 8, 53, 1990.

Kersley, L., Aarons, J., and Klobuchar, J. A.: Nighttime enhancement in total electron content near Arecibo and their association with VHF scintillation, J. Geophys. Res., 85, 4214, 1980.

Kersley, L. and Pryse, S. E.: The development of experimental ionospheric tomography, Int. J. Image Syst. Technol., 5, 141-147, 1994.

Kersley, L., Pryse, S. E., Walker, I. K., Heaton, J. A. T., Mitchell, C. N., Williams, M. J., and Willson, C.A.: Imaging of electron density troughs by tomographic techniques, Radio Sci., 32, 16071621, 1997.

Pryse, S. E., Kersley, L. Williams, M. J., and Walker, I. K.: The spatial structure of the dayside ionospheric trough, Ann. Geophysicae, 16, 1169-1179, 1998.

Walker, I. K., Heaton, J. A. T., Kersley, L., Mitchell, C. N., Pryse, S. E., and Williams, M. J.: EISCAT verification in the development of ionospheric tomography, Ann. Geophysicae, 14, 1413-1421, 1996. 